\title{
Farmers' Perceived Risks and Risk Management Strategies in an Emerging Mussel Aquaculture Industry in Denmark
}

\author{
DEWAN A. AHSAN \\ EVA ROTH \\ University of Southern Denmark
}

\begin{abstract}
The aim of this exploratory study is to provide empirical insight into how mussel farmers perceive and manage risks. The results show that future price, demand for mussels, and changes in public regulation are the high-ranked perceived risks. Bad weather, oxygen depletion, harmful algal blooms (HABs), E. coli, change in governmental regulation, and public views towards mussel culture are also considered important risk factors in mussel farming. On the other hand, production at the lowest possible cost, cooperative marketing, good relations with government, liquidity, adaptation of new technology, and experience sharing are perceived as the most important risk management strategies. When developing and changing policies for farmers' satisfaction and for the long-term sustainability of mussel aquaculture, policymakers should consider these risks and risk management strategies emphasized by the farmers.
\end{abstract}

Key words Risk perception, risk management, seafood markets.

JEL Classification Code Q22.

\section{Introduction}

Perceived risk has been brought to the attention of policymakers and researchers over the past decades. According to Sjoberg (1998), risk perception is all about the thoughts, beliefs, and constructs of human beings. So, risk perception encompasses the mental processing of risk information and coping mechanisms that people use in dealing with uncertain outcomes. Risk perceptions influence an individual's risk-taking behaviour, such as business decisions regarding project initiation and continuation (Keil et al. 2000). Therefore, both finance scholars and investment professionals are aware that an individual's perception of risk might influence business decisions and investment activity. For example, it is an individual's perception of, and ultimately their reaction to, risk that affects stock prices (Farrelly and Reichenstein 1984). Consequently, the actual risk is not the only factor; how investors perceive and react to that risk is also significant. Individuals are prepared to invest more in those financial alternatives that they perceive as less risky (Weber and Hsee 1998). Therefore, it is important to consider how rural communities and farmers perceive risks. A better understanding of farmers' risk perceptions and how those perceptions influence behaviour is integral to developing sustainable land and

Dewan A. Ahsan is a researcher and Eva Roth is an associate professor, Department of Environmental and Business Economics, University of Southern Denmark, Niels Bohrs Vej 9, 6700 Esbjerg, Denmark (email: daahsan@ yahoo.com and er@sam.sdu.dk, respectively).

Financial support for this study was provided by the Danish Agency for Science, Technology, and Innovation through the MarBioShell project. We are grateful to Lars Ravn-Jonsen for his assistance in modeling and Asger Stensig Koppen for assisting during the interview process. 
natural resource use and effective management policies and programs which are supported and implemented at local and regional levels (Krogmann, Gibson, and Chess 2001). From a Danish perspective, in the emerging mussel aquaculture industry the risk of failure is very high. Therefore, a focus on risks and risk strategies is a preliminary condition for public management to aid this up and coming industry.

The agricultural sector inherently faces more risks than do most other industries (Geurin and Geurin 1994). Farmers' perceptions of risk and responses to these risks are important in understanding their risk behaviours. Several surveys about risk and risk perception have been conducted in recent years, but most were based on conventional agriculture; specifically dairy and crop producers (Hall et al. 2003; Koesling et al. 2004; Meuwissen, Hurine, and Hardaker 2001; Flaten et al. 2005).

Aquaculture, like any other agri-businesses, is a risky business. Many types of risk are associated with aquaculture; i.e., technical, production, marketing, institutional, personal, and financial risk. Thus, understanding risk is the key element to helping aquaculture producers make better decisions in potentially risky situations. Understanding farmers' risk perception and how they manage risks is also vital to decision makers, private consultants, husbandry, and financial advisers in order to take effective actions to enhance aquaculture businesses. Thus, risk perception and management responses of aquaculture producers' have received little attention in aquaculture economics. However, a few research projects have analysed these farmers' risk perceptions.

Mussel culture is one of the largest aquaculture industries in many countries of the world. Mussel culture in Europe produces about $50 \%$ of the annual worldwide harvest (Smaal 2002). The history of mussel culture in some European countries is very old. Mussel aquaculture in Italy started more than 2,000 years ago (Mattei and Pellizzato 1997). The history of mussel culture in France and the Netherlands is almost 700 years old (Dijkema 1997).

However, mussel culture is very new in Denmark and other Nordic countries. The Danish government started issuing licenses for mussel culture in 2003. Mussel production (from aquaculture) in Denmark comes mainly from the Limfjord. Danish farms primarily produce blue mussels (Mytilus edulis) using long-line mussel farming techniques.

An understanding of mussel farmers' risk perceptions and risk management strategies is important for formulating the proper policy to expand and preserve the sustainability of this industry. To our knowledge, no studies to date have been designed to investigate mussel farmers' risk perception and the ways they deal with the risks. Therefore, the goals of this study are to provide empirical insights into the following questions: $i$ ) What are mussel farmers' objectives, motivation, and goals? ii) How do farmers perceive risk in the mussel farming business? and iii) Which management strategies do the mussel farmers adopt to mitigate those risks?

\section{Materials and Methods}

By 2008 more than 50 licenses for mussel aquaculture had been issued across Denmark. Not all license holders have set up their mussel plants, and presently (2010) 18 mussel farms are in production in Denmark, all in the Limfjord (figure 1).

We hypothesize that Danish mussel farmers have a very clear perception about the sources of risk to mussel culture and how to tackle those risks, because they are well educated and have easy access to information and formal credit systems. However, it is very difficult to develop any strong hypotheses to test due to the absence of similar studies in aquaculture. Thus, an exploratory or discovery-oriented approach was chosen whereby the primary stipulation was that the research should be empirical. To that end, structured (questionnaire surveys) and semi-structured interviews were conducted. We decided to conduct personal interviews using questionnaires in Denmark (October 2008). 
We made appointments with the farmers over the telephone and conducted the interviews door-to-door. Most interviews took place in farmers' homes so as not to encroach upon their time at work and in light of the fact that they do not have offices. Interviewing at home also provided a friendly atmosphere in which to discuss the questionnaire with the respondents. We prepared the questionnaire in Danish, though most Danish farmers are proficient in English. One of our Danish students helped to conduct the interview in Danish to ensure that the farmers could understand all of the questions. We obtained appointments with 14 farmers, and 4 others declined an interview. The response rate was high ( $78 \%$ of the total population).

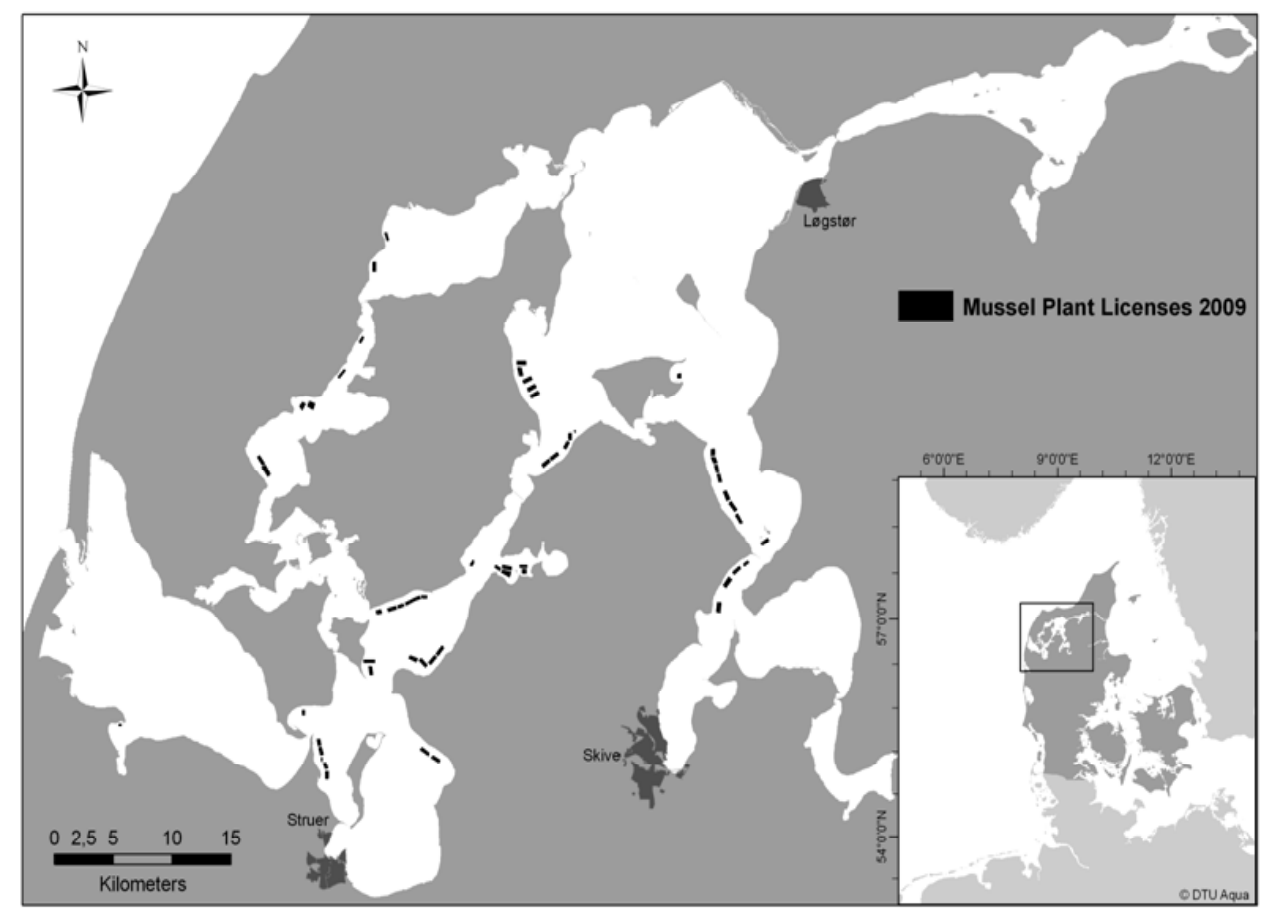

Figure 1. Mussel Plant Licenses Allocated in Limfjord, Denmark, 2009

As Danish mussel farmers have similar socio-economic backgrounds, use the same farming technology, and are located in the same geographic area, we do not expect that the overall results would change if we were to include the remaining four farmers.

The lack of similar studies in aquaculture, especially in mussel farming, led us to plan for inter-industry comparisons. We prepared the questionnaire in a manner similar to previous studies of the livestock and poultry industries in Western Europe (e.g., Flaten et al. 2005; Meuwissen et al. 2001; and Koesling et al. 2004).

The questionnaire included questions related to the following issues: i) farmers' perceptions of risk (including questions on risk attitude and sources of risk); ii) farmers' perceptions of various risk management strategies; iii) farmers' goals, future plans, and motivations for their farming system; and $i v$ ) characteristics of the farm and farmer. Most questions designed to analyse risk perception and risk management strategies were of the 
closed type, mainly in the form of five-point Likert-type scales (Churchill 1995). Sociodemographic characteristics (e.g., age, gender, family size, education level, income, etc.) were also elicited. A pilot testing of the questionnaire was conducted with three of the farmers. The pilot testing resulted in very limited changes, mostly to the Danish wording of the questions (appropriate terminology).

A total of 32 sources of risk and 21 risk management strategies relevant for mussel farmers were presented. Farmers were asked to score each source of risk on a Likert-scale from 1 (not relevant) to 5 (very relevant) to express how significant they considered each source of risk in terms of its potential impact on the economic performance of their farm. Similarly, the importance of each risk management strategy was scored on a Likert scale from 1 (not relevant) to 5 (very relevant).

Simple descriptive statistical methods were used to analyse the results. We were unable to use standard multivariate techniques for data analysis because the population size was not large enough (Hair et al. 1998).

\section{Result and Discussion}

The characteristics of the farms and the farmers' obtained from the present study are presented in table 1 . The result shows that there are differences in the way the farmers are organised. Eight of the respondents have personal ownership of their farms, five are organised as limited partnerships (Danish ApS), and one is organised as a limited company (Danish A/S) that facilitates the marketing of the mussels. Ten farmers are completely dependent on mussel farming, and those remaining are part-time mussel farmers. The average farm size is 34.05 ha. The average education level is 11.50 years. Our study also found that three farmers had MSc degrees in biology. About 50\% of the farmers have had formal training in mussel culture.

The main objective of the farmers is to achieve positive net outcomes within a few years. Only four respondents informed us that they were making a very marginal profit from mussel farming, whereas the other ten were taking a loss. This finding is consistent with official aquaculture accounting statistics defining net profit as (Danish Account Statistics 2007):

Total gross output - Total cost - Depreciation $=$ Net profit.

At present, investment costs and thus depreciation are high and the learning curve is steep. This information is also corroborated by Danish aquaculture statistics, which indicate that production is increasing every year and that net negative profit is decreasing. The data are based on accounts for 2006 and 2007 because mussel farming is an emerging industry and was not established before 2003. No account figures are published for 2003-2005 because mussel seeds need at least 18 months to achieve a marketable size. In 2006, total mussel production was 650 tons with a gross output of 853,000 USD. However, the total negative net profit was 550,000 USD in 2006. Total mussel production increased to 1,066 tons in 2007 (total gross output 1,688,000 USD), which resulted in a net negative profit of around 123,000 USD (Danish Aquaculture Account Statistics 2006, 2007). It is notable that the total loss was reduced by 377,000 USD in 2007. The farmers expected much better economic results in 2008, but their accounts have not yet been audited. 
Table 1

Description of Farm and Farmer Characteristics of Danish Mussel Farmers

\begin{tabular}{lcc}
\hline Characteristics & Farm in Survey & Range \\
\hline Full-time farmer & 10.00 & \\
Part-time farmer & 4.00 & \\
Personally owned farm & 8.00 & \\
ApS (Limited partnership) & 5.00 & \\
AS (Limited company) & 1.00 & $2-48$ \\
Average farm labor units (man-months) & & $2-12$ \\
$\quad$ i) Employee & 14.00 \\
$\quad$ ii) Owner & 8.18 & \\
Average farm area (ha) & 34.05 & $20-57$ \\
Age of farmer (years, average) & 42.24 \\
Family size (average) & 3.58 & $1-5$ \\
Average education (years) & 11.50 & $10-$ Masters \\
Average farm experience (years) & 3.88 & $2-6$ \\
Mussel farming training (\%) & 50.00 & \\
Farm gross annual income in 2009 (DKK) & Loss (for 9 farms) & \\
\hline
\end{tabular}

\section{Farmers' Motivations for Mussel Farming}

We provided the following seven options to determine the farmers' motivations for mussel farming: mussel farming provides more income than other fish farming (MF), it provides more income than other agri-business (MG), mussel farming gives stable income (SI), I set up a mussel farm due to my educational background in biology (BB), mussel farming requires less capital (LC), it is my family business (FB), and mussel farming is my hobby (MH) (figure 2). The results indicate that 30\% of the farmers are involved in mussel farming because they have a strong educational background and work experience in fish culture. About $20 \%$ of the respondents stated that mussel farming requires less capital than other agri-businesses, and this is the reason they have chosen mussel farming as their profession. Around $20 \%$ started mussel farming as a hobby. Others are involved in mussel farming because it provides more income than other fish farming or because they were attracted by the fact that mussel farming requires only simple technology. Ahsan (2009) reported that 70\% of Bangladeshi shrimp farmers are involved in the shrimp farming business because they think that shrimp farming generates more income than other agri-businesses. However, a significant percentage (18\%) of the shrimp farmers reported that they were in business because "they do not have any alternative local job opportunity available" (Ahsan 2009).

Strong core competencies and a likely perceived competitive advantage for this new Danish industry underscore the benefits of education within specialised fields as motivation for the development of a new industry. Economic potential or restraints are likewise motivating factors for many entrepreneurs. Making your hobby your profession is a very personal motivational factor, which hardly can be replicated as a social incentive for the general public. 


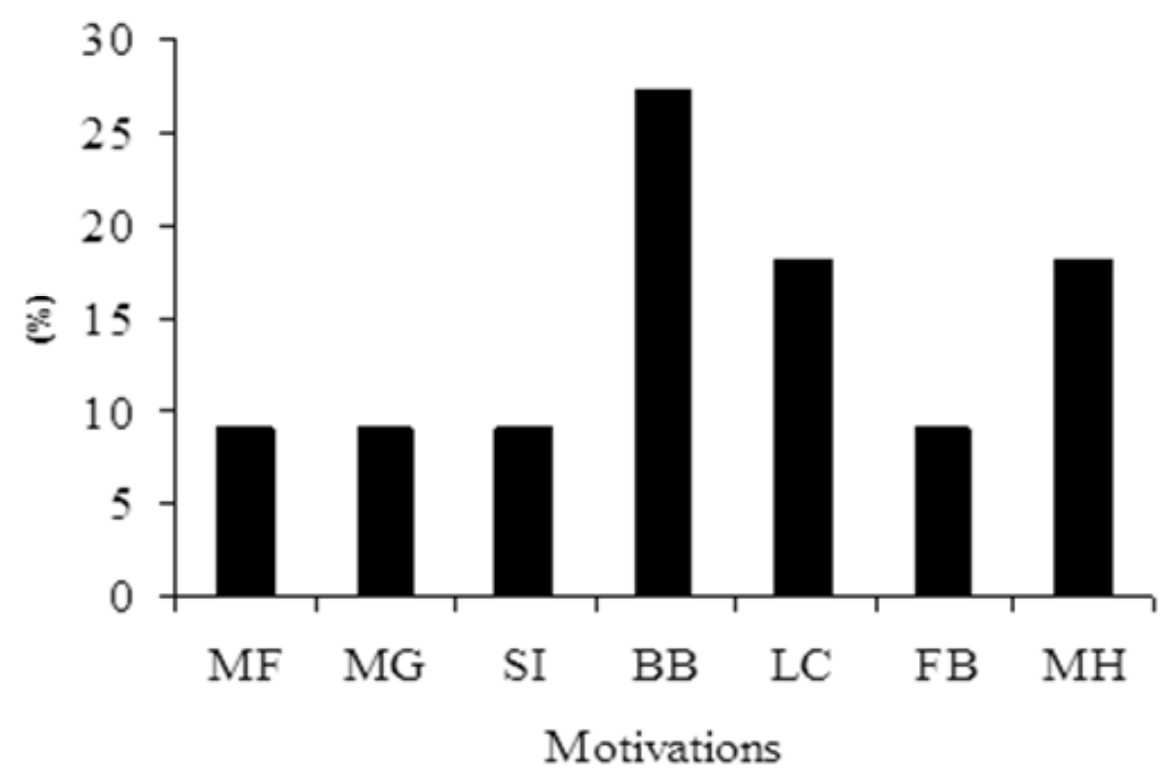

Figure 2. Motivations for Mussel Farming

Notes: $\mathrm{MF}=$ Mussel farming gives more income than other fish farming; $\mathrm{MG}=$ It provides more income than other agro-businesses; SI = Mussel farming gives stable income; BB = Educational background in biology; LC $=$ It requires less capital; $\mathrm{FB}=\mathrm{It}$ is my family business; $\mathrm{MH}=$ Hobby.

\section{Marketing of Mussels}

Mussels produced in Europe are predominantly consumed within Europe, and it is one of the major internal forms of trade between neighbouring countries (Monfort 1999). In fact, fresh mussels and mussel products are not a traditional food in the Danish kitchen. Therefore, the mussel industry in Denmark depends heavily on inter-European exports. We found $94 \%$ of the production to be exported to other European markets. Only $6 \%$ of the production (according to our survey data) goes to the domestic market. Holland is the main market for Danish mussels, importing $80 \%$ of the production. The other $14 \%$ goes to the Belgian and French markets. All mussels are sold fresh. This study revealed that the owners of small farms market their production through a cooperative to improve distribution capacity and create a significant volume for potential buyers. Some of the owners of small farms also sell their product directly to the distributor. On the other hand, the companies (A/S and ApS) with higher production capacities export their product directly. Farmed mussels are marketed fresh for two reasons: first, the price of fresh mussels is much higher than that of mussels supplied for processing, and second, mussel growers can better supply fresh product in the required quantities at a designated time in line with buyers' demand than can fishermen.

\section{Farmers' Future Plans}

To explore mussel farmers' future plans, we set the following four statements: I would like to expand the farm area, I would like to increase production, I plan to use new technology, and I want to leave the business. We asked the farmers to answer dichotomously 
(either "yes" or "no"), and multiple answers were allowed. The summary of the responses is shown in figure 3. All the farmers aim to increase their farm production in the future. Fifty percent of the farmers wish to increase their farm area by acquiring more licenses. It is surprising that no one is interested in giving up the business, despite the fact that many of them are not making any profit. We asked the farmers why they are confident in running the business even though they are presently taking a loss from the mussel business. In reply, all of them stated that they are quite new in this business and still in the learning stage. Thus, they believe that the business will be profitable in the near future as their practical experience accumulates.

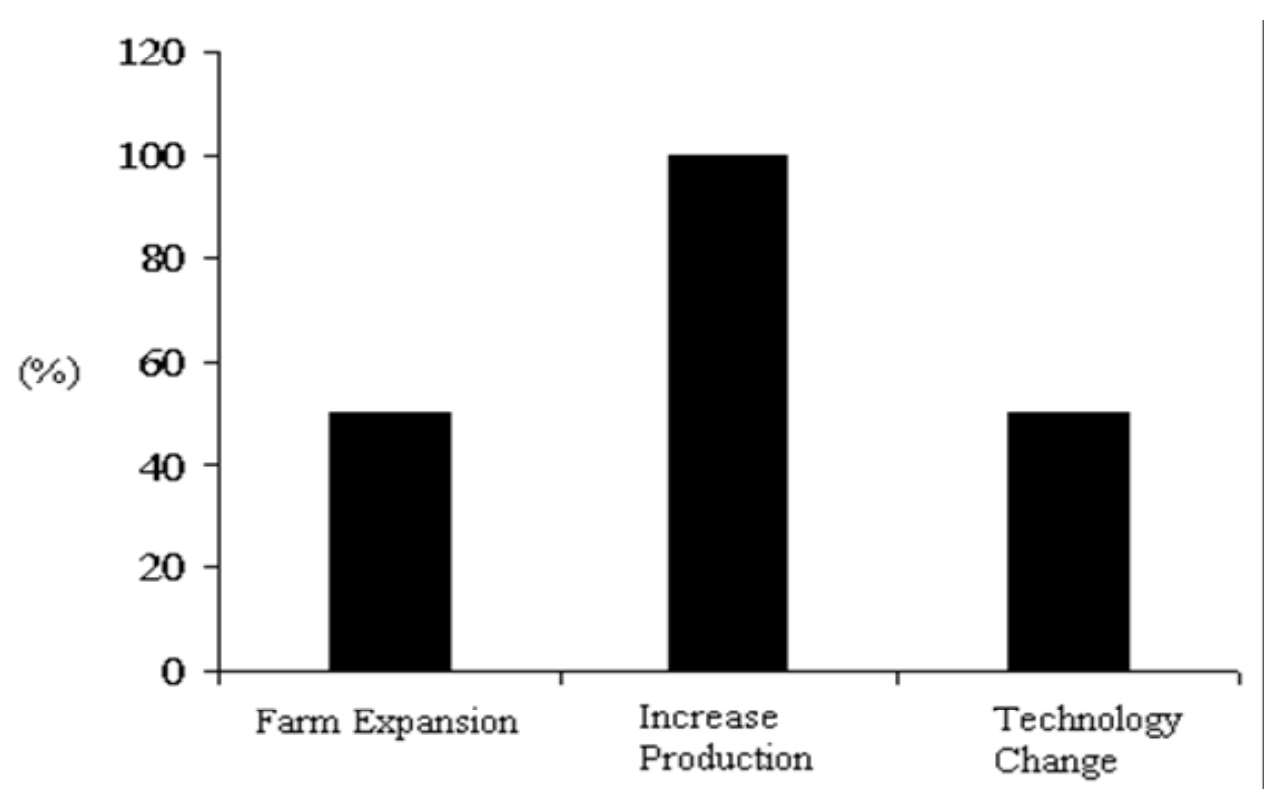

Figure 3. Mussel Farmers' Future Business Plan

\section{Farmers'Perceptions of Risk Sources}

We included 31 different types of risk-related questions in the questionnaire. The questions were divided into five risk subgroups termed: production, marketing, financial, human, political, and social risk. The results are reported in table 2.

Bad weather, harmful algal blooms (HABs), oxygen depletion, and E. coli were perceived as important risks to production. In fact, oxygen depletion and HABs seem to be potential threats to mussel farming because almost $50 \%$ of the farmers lost income due to these factors during 2006-2008. The monitoring of phytoplankton in shellfish culture areas extends along the entire Atlantic and North Sea coasts, owing to national and EU regulations (ICES 1999).

When considering market-related risks, future mussel demand and future mussel prices are the highest ranked. Basically, the mussel industry in Denmark is export-oriented and an increase in demand has been observed in the last decade. Consequently, prices have increased (Smaal 2002). So, any price fluctuations in the European market, especially in Holland, directly influence the Danish mussel industry. Several studies have also 
noted that farmers from both developed and developing nations are also concerned about the future demand for and price of their products (Lien et al. 2006; Bergfjord 2009; Meuwissen et al. 2001; Martin 1996). Mussel certification and influence of distributor were also considered important marketing-related risk factors.

Table 2

Farmers' Perceived Sources of Risks in Mussel Aquaculture (Average Scores: 1 = Not Relevant; 5 = Very Relevant)

\begin{tabular}{|c|c|c|}
\hline Risk Sources & Mean & $\mathrm{SD}$ \\
\hline \multicolumn{3}{|l|}{ Operational Risk } \\
\hline Bad weather & 3.50 & 0.99 \\
\hline HABs (harmful algal blooms) & 3.33 & 0.98 \\
\hline Oxygen depletion & 3.25 & 1.60 \\
\hline E. coli & 3.11 & 1.10 \\
\hline Accident by small boats & 2.91 & 1.10 \\
\hline Uncertainty about the future productivity & 2.64 & 1.10 \\
\hline Technical failure & 2.42 & 0.51 \\
\hline \multicolumn{3}{|l|}{ Market Risk } \\
\hline Future mussel demand & 4.32 & 1.00 \\
\hline Future mussel price & 4.13 & 1.10 \\
\hline Mussel health/quality (certification) & 3.50 & 1.70 \\
\hline Influence of middle men or distribution organization & 3.42 & 0.99 \\
\hline Logistics and transportation issues & 3.17 & 1.10 \\
\hline Price of farm equipment & 2.58 & 1.10 \\
\hline \multicolumn{3}{|l|}{ Financial Risk } \\
\hline Loss of equity & 2.67 & 1.30 \\
\hline Guarantees (from distributor or buyers) & 2.55 & 1.20 \\
\hline Future wages of labour & 2.42 & 1.20 \\
\hline Supply of private capital (debt, equity, etc.) & 2.17 & 1.20 \\
\hline Future interest rate & 1.92 & 0.90 \\
\hline Future exchange rate & 1.42 & 0.50 \\
\hline \multicolumn{3}{|l|}{ Political and Social Risk } \\
\hline Change in regulation & 4.28 & 0.90 \\
\hline Public view of mussel farms & 4.12 & 1.00 \\
\hline Uncertainty about food safety policy & 2.92 & 1.10 \\
\hline Future changes in licensing system & 2.67 & 1.30 \\
\hline Uncertainty about trade policy & 2.50 & 1.10 \\
\hline Protest from environmentalist group & 2.42 & 0.99 \\
\hline Market regulation measures & 2.42 & 1.10 \\
\hline Govt. subsidies to mussel farming & 2.36 & 1.40 \\
\hline Taxation & 2.08 & 1.30 \\
\hline \multicolumn{3}{|l|}{ Human Risk } \\
\hline Risk of injuries among employees & 2.91 & 0.83 \\
\hline Loss of key employees & 2.60 & 1.20 \\
\hline Sufficient supply of competent labour & 2.42 & 1.30 \\
\hline
\end{tabular}

Regarding financial risk sources, we considered six different types of risks; i.e., supply of capital, buyer's guarantee, loss of equity, future labor wages, future interest rate, 
and future exchange rate. None were perceived as "most important," as shown by the relatively low rankings. However, loss of equity is considered an important financial risk relative to other types of financial risks. This finding indicates that the farmers assume that financial risk is not a big issue for them, but the low scrap value due to limited alternative use of production equipment is of concern.

Nine different types of risk sources were listed in the questionnaire to ascertain the political and social risks involved in mussel farming. Changing of regulations and public views towards mussel farming were the two top-rated risk sources for the farmers (table 2). This finding indicates that farmers are worried about political risks. Sonkilla (2002) also found changes in agricultural policy to be the most important risk source for Finnish agro-farmers. MacAlister et al. (1999) considered environmental measures as major constraints for mussel culture in some areas, particularly for the collection of seed.

Our questionnaire was also designed to sort out the human risks related to mussel farming. Farmers perceived risk of injuries to them and their employees as important sources of human risk. The farming of mussels is, at present, dependent on manpower because "husbandry" efforts determine the quality (and thereby the price) of the final product. Farmers need to work at sea from a boat. Their working environment is exposed to changing weather conditions. Any place of work at sea is prone to health and safety issues and is rightly considered an important human risk.

\section{Perceived Risk Management Strategies}

Farmers were asked to score 21 different types of risk management strategies according to their importance in mussel culture (table 3). Produce at lowest possible cost was considered the most important risk management strategy. Norwegian salmon and dairy farmers reported similar risk management strategies (Bergfjord 2009; Lien et al. 2006). Cooperation with other farms and cooperative marketing were the next top-ranked risk management strategies. The owners of the privately owned farms stressed these two issues. In fact, a cooperative marketing strategy is very helpful for small farmers in significantly reducing business risk. Denmark was the pioneer for the farmers' cooperative movement. The first dairy farmers' cooperative, established in 1882, is one of the oldest cooperative societies in the world. So, it is not very difficult to see why Danish mussel farmers place much more emphasis on cooperative marketing and knowledge sharing among farmers as strategic moves to reduce the risks in business.

Prioritise liquidity and solvency were also considered very important risk management strategies. Bardhan et al. (2006) made a similar observation regarding Indian dairy farmers. In Norway, Lien et al. (2006) found keeping cash at hand to be the most important risk management strategy for all dairy farmers. Maintain good relations with government and adopt new business technologies were also considered useful risk management tools. Previous studies in agriculture and aquaculture also indicate that farmers are keen to maintain good relations with government and adopt new technology to enhance production (Ahsan 2009; Bergfjord 2009; Lien et al. 2006). Farmers wish to take part in policy formulation and implementation of strategies. So, a good relationship between farmers and the government can significantly reduce political and institutional risk. In fact, above-mentioned risk management strategies are the most commonly applied tools for minimising the risk of economic externalities from public regulations in agribusiness. So, the result of our study indicates that the mussel farmers have very clear ideas on how to handle public institutional pressure. Moreover, the variances of mean of these strategies are less than one, indicating strong consensus on these risk management strategies. In fact, by law the Danish Ministry of Food, Agriculture, and Fisheries is obliged to establish an advisory committee on mussel production that includes a representative of the mussel growers' association. This committee has the right to hear in advance 
all policy matters concerning the regulation of and changes to the existing management framework in relation to mussel trade and industries. So, mussel farmers have the right and access to take part in all policy formulation steps and implementation processes.

Table 3

Farmers' Perception of Different Risk Management Strategies (Average Scores: 1 = Not Relevant; 5 = Very Relevant)

\begin{tabular}{lcc}
\hline Risk Management Strategies & Mean & SD \\
\hline Produce at lowest possible cost & 4.50 & 0.67 \\
Cooperation with other farms & 4.33 & 0.88 \\
Cooperative marketing & 4.30 & 1.31 \\
Prioritize liquidity & 4.30 & 0.62 \\
Experience sharing with other mussel farmers & 4.25 & 0.62 \\
Solvency & 4.17 & 0.62 \\
Maintain good relations with government & 4.10 & 1.08 \\
Adopt new technology & 4.00 & 1.04 \\
Insurance against damage to farm & 3.75 & 1.21 \\
Market monitoring & 3.25 & 1.05 \\
Diversification of products (within Denmark) & 3.10 & 1.66 \\
Buy flexible farm equipment & 3.00 & 1.52 \\
Vertical integration & 3.00 & 1.53 \\
Off-farm work & 2.92 & 0.90 \\
Production contracts & 2.83 & 1.03 \\
Diversification of products (internationally) & 2.36 & 1.62 \\
Have training on farm management & 2.33 & 1.15 \\
Documentation of production factors & 2.33 & 1.30 \\
Horizontal integration & 2.25 & 1.28 \\
Use of veterinarian consultants and service & 1.17 & 0.57 \\
Prevent disease & 1.00 & 1.03 \\
\hline
\end{tabular}

Use of veterinarian service and disease prevention were the bottom-rated riskmanagement strategies. In fact, disease is not a big problem in mussel farming compared to other fish or shellfish farming ventures. We included this question solely to assess the farmers' knowledge, and they responded accordingly by mentioning that disease prevention is not an important risk-management tool for them.

Farmers reported HABs and oxygen depletion to be important threats to production. Clear knowledge of the causes of mussel mortality and mussel marketing constraints is important in order to become a successful mussel farmer. The results of our study indicate that Danish mussel farmers have extensive knowledge on the mortality and marketing restraints due to HABs and oxygen depletion, and at the same time they do not confuse these issues with disease infected mortality.

\section{Scientific and Policy Response to Economically Sustainable Mussel Farming}

Scientifically, we can analyse the findings of the general economic status of the industry, the future plans (figure 3), and the questions asked on farm economics. The individual economic data cannot be presented due to discretionary conditions (the number of re- 
spondents are few), as every farmer in the community would be able to recognise the individuals behind the data.

To establish whether the farmers' future plans to turn losses into net profits are viable, a simple model was developed using a Cobb-Douglas production function (Cobb and Douglas 1928):

$$
\mathrm{Y}=\alpha \mathrm{A}^{\beta} \mathrm{L}^{\gamma}
$$

The model represents mussel production, where shell production $Y$ (tons per year) is determined by the input factors labour $L$ (months) and area $A$ (ha). The two control variables, $L$ and $A$, are set by the farmer, and the model assumes that the farmer, given the cost, price, and restrictions on farming, maximises the contribution margin. The parameters $\alpha$ is the total factor productivity, and $\beta$ and $\gamma$ are the output elasticities of area and labour, respectively.

The farmers' behaviours are driven by restrictions in area and an aim to maximise the contribution margin. The farmer is restricted in the input of area $A$ by a licensing system, setting the maximum allowable area for the individual license holder to $250 \times 750 \mathrm{~m}^{2}$. Larger companies consist of two or more license holders.

We used 14 data sets from our survey and 11 data sets from the Danish national account statistics of aquaculture production in the Limfjord (those statistics reflect only four companies in 2006 and seven in 2007) to establish the production function (especially questions on production, labour in man-month wages, and farm gate prices). The farmers reported the data for labour, area, and expected yield. The parameters $\alpha, \beta$, and $\gamma$ were estimated in a logliner model. Based on the farmers' expectation, the estimated parameters for the model are:

\begin{tabular}{ccc}
\multicolumn{3}{c}{ Value Std. Error } \\
$\alpha$ & 2.5380 & 4.1813 \\
$\beta$ & 0.4195 & 0.4843 \\
$\gamma$ & 0.7043 & 0.7167.
\end{tabular}

This model produces a mean production function. To convert the mean production function into a production possibility frontier, the production function was inflated by a factor of 1.3 . The production possibility frontier then enveloped $80 \%$ of the values expected by the farmers. This gives the following parameters used in the model:

$$
\begin{gathered}
\alpha 3.2994 \\
\beta 0.4195 \\
\gamma 0.7043 \text {. }
\end{gathered}
$$

Because it is based on farmers' expectations given in the interviews, the production possibility function (Cobb-Douglas) with these parameters must be viewed as a model that describes the expectations of the farmers. Intuitively, the function is the frontier at which farmers optimise their net profit within the present constraints of investments, technology, and production methods.

\section{Cost and Price for Farmers}

The only cost considered in this model is labour. The model further mirrors the market because size, meat content, appearance, and uniformity command a higher price, and these attributes are dependent on husbandry efforts. The quality and extent of care given to the mussels increases their quality, and because the size of the mussel plants are given by the licenses, the investments only depreciate for a few years and innovations are not included. 
The labour cost is set to $W=3,894$ Euro per month (from interview). The ex-farm price of blue mussel production for the seven companies in the account statistics of aquaculture production in the Limfjord in 2007 are in the range 0.567 to 1.3420 Euros per $\mathrm{kg}$. According to the interviews, the quality and therefore the ex-farm price, is dependent on the intensity of the labour (husbandry). Consequently, the price function is estimated as a linear increasing function of labor input, $\mathrm{x} \mathrm{ha}^{-1}$, establishing the quality/ price relationship:

$$
p(L, A)=\left\{\begin{array}{cc}
0.567 & \frac{L}{A}<0.4 \\
-0.753+3.3 \frac{L}{A} & 0.4<\frac{L}{A}<0.635 \\
1.342 & 0.635<\frac{L}{A}
\end{array}\right.
$$

The values 0.4 and 0.635 represent the minimum and maximum expected labour intensity, respectively. The results of our model are illustrated in figure 4.

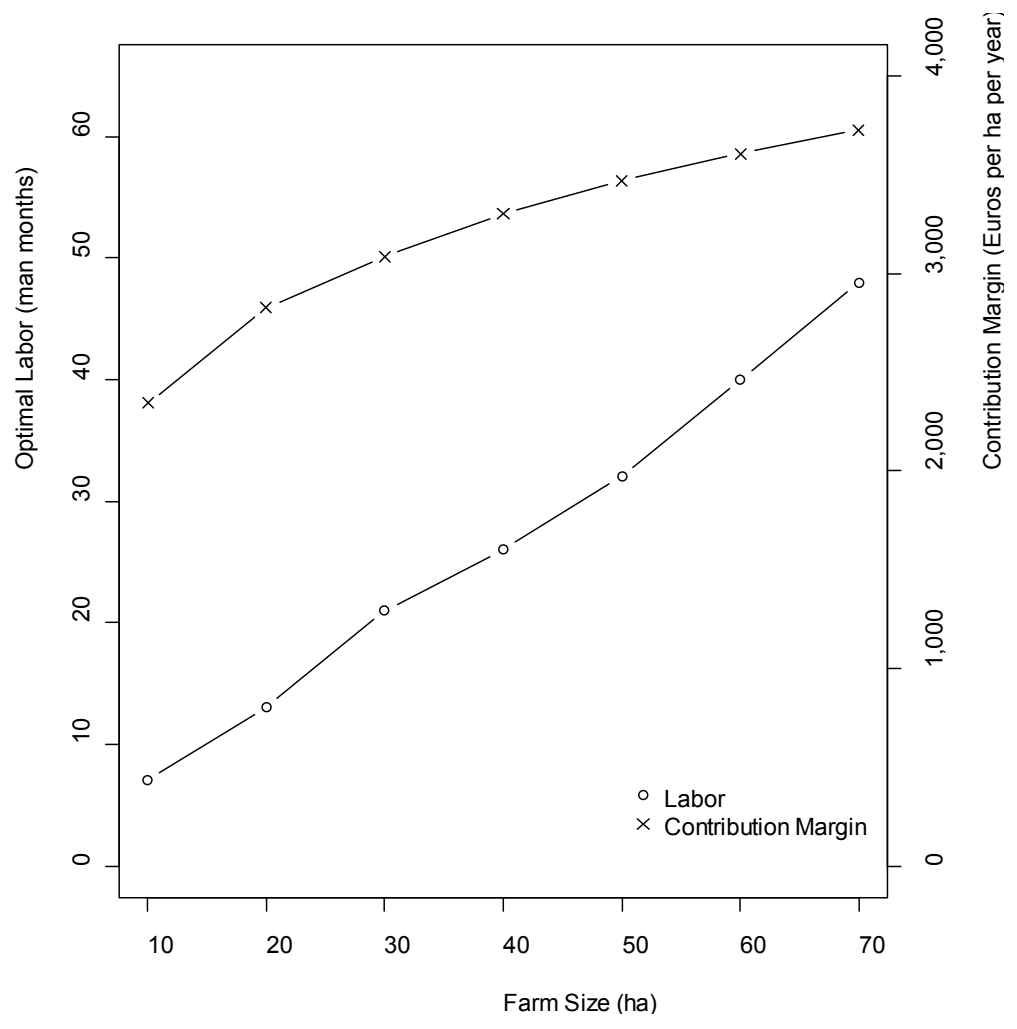

Figure 4. Results from the Mussel Production Function Model 
The results show that larger farm sizes and thereby higher yearly productions (economies of scale) increase the margin of contribution per hectare of farm and thereby increase the rentability of the farms. Farm size is in the range from 10-70 HA because no Danish mussel farm company has access to more than $70 \mathrm{HA}$ of production area. From an empirical point of view, the strategy of larger production and larger acreage farms improves economic sustainability and decreases the risk of losses. Politically, this result implies failure of the management system to supply licenses of a size in agreement with economic rationale. The reason for the small plot licensing system might be rooted in consideration of the environmental impacts of farms and access limitations to fishermen, yachting, and other activities in the coastal zone competing with mussel farmers, which are not fully scientifically documented.

The important fact that we might take into consideration is that the farmers are strongly motivated to continue the business because they have accepted that they are in new industry where they may take a loss in the early stages, but higher income will follow. Farmers are confident, despite a steep learning curve. Farmers' motivations and expectations are in line with the economic opportunities modeled by the production function.

This study also revealed that the labor input has effects on mussel quality (e.g., by removing anti-fouling agents from shells and sorting them into proper sizes) and hence, on price. Therefore, the established price function may help mussel farmers adopt the proper management strategies to drive their development in an economically sustainable way. However, it is necessary to mention that the results are based on the model assumption and an emerging industry. So, it is not possible to demonstrate the statistical significance of the model.

\section{Conclusion}

The significant finding of this study is that Danish mussel farmers have a clear perception of various sources of risk related to their business, and they also have a clear strategy for how to handle those risks. There are many examples. Market price fluctuations pose an economic risk to the farmers. A strategic response to reduce this risk is for the farmers to enter into cooperative marketing. Cooperative marketing supports more stable farm gate prices for the individual by pooling produce and meets the demand for larger quantities and a stable supply during the different seasons. The risk of frequent changes of policy and thereby regulations on their production poses a high risk for continuity. To plan for the future and develop technology suitable for their production, the farmers need predictable regulation, and any changes should ideally improve these conditions. The farmers' perceived strategy for dealing with this risk is to keep close contact with the political system, a right they hold through consultation on changes in the advisory committee for mussel production. The strategy is sound but does not eradicate the full risk of marketing and policy changes.

In regards to strategies for hedging marketing and policy risks, we detect mismatches in farmer's perceptions and their economic behaviours. For instance, farmers are very rightly worried about future mussel demand and price development; however, production contracts and diversification of products (within and outside of Denmark) were not perceived as important risk-management tools (although the standard deviation is very high) to mitigate marketing risks. Production contract and product diversification are the most important tools to reduce price and demand risks. Monfort (1999) mentioned that musselbased, value-added products like individual quick frozen mussels, ready meals, and breaded products are vital for increases in trade volume and profits from mussel farming. However, we notice that Danish mussel farmers have no clear concept of production diversification like branding or private labeling as risk management tools. That finding indicates that farmers do not have a strategic vision for price risk mitigation. 
Policy changes aimed at reducing marketing risks are not an economically recommendable solution if the market is competitive in the true sense of the word. If market failure is the cause of low farm gate prices (oligopsony, imperfect information), government regulations might result in "Pareto" improvements to society (and the farmers), but economic theory predicts societal losses with the introduction of market regulations in a well-functioning competitive market, which, in turn, would contradict good public management practices.

Financial risks are perceived as fairly low by the farmers. This mirrors a "prefinancial crisis" situation where capital was fairly easy to acquire, either through banks or private investors, as so-called "risk willing private capital." A similar study today might show a different result. The strategic management strategies adopted by the farmers decrease the risks, but do not eliminate the very large fluctuations in the business. To produce at lowest possible cost (scored 4.5 out of 5, on average), prioritise liquidity (4.30), and solvency (4.17) are evidently the most rational economic choices to make in any business, but cooperation with other farmers (4.33), cooperative marketing (4.30), and experience sharing with other farmers (4.25) were perceived as more important than direct competition between the farmers in this specific, new, and growing industry. Public support for knowledge creation and dissemination may therefore further aid this process. The strategy for handling political and social risks is maintaining good relations with government (4.10). This decision is not necessarily a sufficient strategic move for the farmers. This risk ought to be more specifically reduced through policy intervention so as to create a long-term planning period for changes influencing aquaculture operations; i.e., long-term licenses, changes in management planned over longer time periods, etc.

The last point we want to make is the call for new technology. The farmers score adaptation of new technology at 4.00, which is high. The potential for higher productivity due to new technology is perceived to be present in the industry, and because these small farmers do not have the capacity to develop new technology on their own, a targeted research effort for new technological development could be subsidised through public funds. Results of our study could also provide some useful guidelines to policymakers for formulating sustainable policies and establishing suitable management strategies.

\section{References}

Ahsan, D.A. 2009. Shrimp Farmers' Risk Perceptions and Risk Management Strategies: Empirical Evidence from Bangladesh. Presented at World Aquaculture Society Conference, Veracruz, Mexico.

Bardhan, D., Y.P.S. Dabas, S.K. Tewari, and A. Kumar. 2006. An Assessment of Risk Attitude of Dairy Farmers in Uttaranchal (India) <http://ageconsearch.umn.edu/ bitstream/25259/1/cp060849.pdf>.

Bergfjord, O.J. 2009. Risk Perception and Risk Management in Norwegian Aquaculture. Journal of Risk Research 12:91-104.

Churchill, G.A. 1995. Marketing Research Methodological Foundations. New York, NY: The Dryden Press.

Cobb, C.W., and P.H. Douglas. 1928. A Theory of Production. American Economic Review 18:139-65.

Danish Aquaculture Account Statistics. 2006. Report on Aquaculture $<$ http://www.foi. life.ku.dk/Nyheder/Nyheder\%202008/ /media/Foi/docs/Publikationer/Statistikker/ Ak akultur/Serie_H_2006.ashx>. 2007. Report on Aquaculture <http://www.danskakvakultur.dk/files/rapporter/ Serie\%20H\%202007.pdf>.

Dijkema, R. 1997. Molluscan Fisheries and Culture in The Netherlands. NOAA Technical Report, NMFS 129:115-36. 
Farrelly, G.E., and W.R. Reichenstein. 1984. Risk Perceptions of Institutional Investors. Journal of Portfolio Management 10:5-12.

Flaten, O., G. Lien, M. Koesling, P.S. Valle, and M. Ebbesvik. 2005. Comparing Risk Perceptions and Risk Management in Organic and Conventional Dairy Farming: Empirical Results from Norway. Livestock Production Science 95:11-25.

Geurin, L.J., and T.F. Geurin. 1994. Constraints to the Adoption of Innovations in Agricultural Research and Environmental Management: A Review. Australian Journal of Experimental Agriculture 34:549-71.

Hair, J., J.F. Anderson, R.E. Tatham, and W.C. Black. 1998. Multivariate Data Analysis. Upper Saddle River, NJ: Prentice Hall.

Hall, D.C., O.K. Thomas, E. Allan, H.C. Keith, and F.P. George. 2003. Analysis of Beef Producers' Risk Management Perceptions and Desire for Future Risk Management Education. Review of Agricultural Economics 25:430-48.

ICES. 1999. Report of the ICES-IOC Working Group on Harmful Algal Bloom Dynamics. ICES cm 1999/C: 4.

Keil, M., L. Wallace, D. Turk, G. Dixon-Randall, and U. Nulden. 2000. An Investigation of Risk Perception and Risk Propensity on the Decision to Continue a Software Development Project. Journal of Systems and Software 53:145-57.

Koesling, M., M. Ebbesvik, G. Lien, O. Flaten, P.S. Valle, and H. Arntzen. 2004. Risk and Risk Management in Organic and Conventional Cash Crop Farming in Norway. Acta Agriculturae Scandinavica, Sectection C 1:195-206.

Krogmann, U., V. Gibson, and C. Chess. 2001. Land Application of Sewage Sludge: Perceptions of New Jersey Vegetable Farmers. Waste Management Research 19:115-25.

Lien, G., O. Flaten, A.M. Jervell, M. Ebbesvik, and P.S. Koesling. 2006. Management and Risk Characteristics of Part-time and Full-time Farmers in Norway. Review of Agriculture Economics 1:111-31.

MacAlister, E. 1999. Forward Study of Community Aquaculture. EU DG XIV Report, EU, Brussels.

Martin, S. 1996. Risk Management Strategies in New Zealand Agriculture and Horticulture. Review of Marketing and Agricultural Economics 64:31-44.

Mattei, N., and M. Pellizzato. 1997. Mollusk Fisheries and Aquaculture in Italy. NOAA Technical Report, NMFS 129:201-16.

Meuwissen, M.P.M., R.B.M Hurine, and J.B. Hardaker. 2001. Risk and Risk Management: An Empirical Analysis of Dutch Livestock Farmers. Livestock Production Science 69:43-53.

Monfort, M.C. 1999. The European Market for Bivalves. FAO/Globefish Research Programme, Vol. 62, Rome.

Sjoberg, L. 1998. World Views, Political Attitudes and Risk Perception. Risk, Health, Safety and Environment 9:137-52.

Smaal, A.C. 2002. European Mussel Cultivation along the Atlantic Coast: Production Status, Problems and Perspectives. Hydrobiologia 484:89-98.

Sonkilla, S. 2002. Farmers' Decision-making on Adjustment into the EU. Publication No. 34, Department of Economics and Management. Helsinki: University of Helsinki.

Weber, E.U., and C. Hsee. 1998. Cross-cultural Differences in Risk Perception, but Cross-cultural Similarities in Attitudes towards Perceived Risk. Management Science 44:1205-17. 
